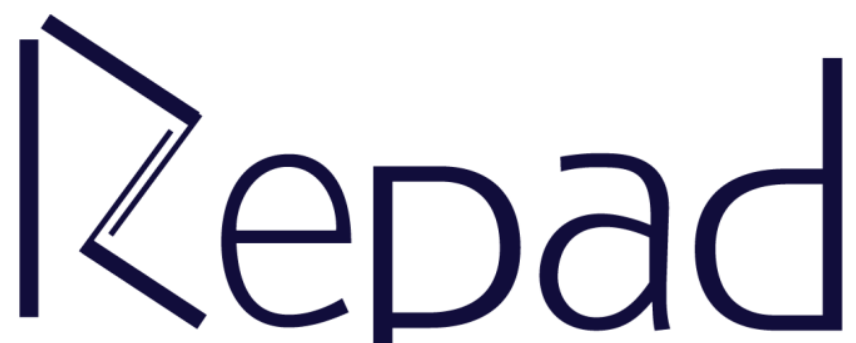

vol. 3, n. 3, Setembro-Dezembro/2019

Revista Estudos e

Pesquisas em Administração 


\title{
A PERCEPÇÃO DA COMUNIDADE ESCOLAR QUANTO AO PERFIL DO GESTOR DIANTE DO PROCESSO DE GESTÃO DEMOCRÁTICA
}

\author{
Nádia Ligianara Dewes Nyari \\ Faculdade La Salle, Lucas do Rio Verde, Mato Grosso, Brasil \\ https://orcid.org/0000-0003-0237-5116 \\ e-mail: nadialigianara@hotmail.com \\ Marcos Alves De Souza \\ Universidade de São Paulo - Escola Superior de Agricultura "Luiz de Queiroz" - \\ ESALQ - USP, Sorocaba, São Paulo, Brasil \\ https://orcid.org/0000-0002-2327-2784 \\ Geverson Tobias Böhm \\ Faculdade La Salle, Lucas do Rio Verde, Mato Grosso, Brasil \\ https://orcid.org/0000-0003-0194-812X \\ Sandra Ines Horn Bohm \\ Faculdade La Salle, Lucas do Rio Verde, Mato Grosso, Brasil \\ https://orcid.org/0000-0002-3264-7314
}

\section{Resumo}

O objetivo deste estudo foi analisar a percepção da comunidade escolar sobre o perfil do diretor/gestor da realidade da gestão democrática, enfatizando primeiro alguns pontos descritivos, permitindo uma conceituação sobre a gestão do tema e suas relações, com a intuição de destacam seu condicionamento social e capitalista, a serviço dos objetivos autoritários propostos. Posteriormente, a pesquisa apresentou uma abordagem exploratória qualitativa, baseada na aplicação de um questionário para verificar as causas do problema. Os resultados destacaram o entendimento da comunidade escolar sobre o papel do diretor / gerente dentro do sistema, mas esse processo não está totalmente implementado ou consolidado, causando confusão com o perfil do diretor/gestor no ambiente educacional. No entanto, a participação da comunidade escolar na implementação da gestão democrática desempenha um papel de extrema relevância e importância, como apontado pela pesquisa, mesmo sendo muitas vezes esquecido pelo grupo escolar, que ainda hoje descreve o diretor/gestor como um líder autoritário, com algumas habilidades que podem enfatizar o saber ouvir e a capacidade de dialogar, especialmente incentivando a participação da escola no contexto escolar.

Palavras-chave: Participação, liderança, ambiente escolar, conhecimento.

\section{THE SCHOOL COMMUNITY'S PERCEPTION OF THE MANAGER'S PROFILE IN VIEW OF THE DEMOCRATIC MANAGEMENT PROCESS}

\begin{abstract}
The purpose of this study was to analyze the perception of the school community regarding the profile of the principal/manager from the reality of democratic management, emphasizing first some descriptive points, allowing a conceptualization on the theme management and its relations, with the intuition to highlight their social and capitalist conditioning, in the service of the proposed authoritarian objectives. Subsequently, the research presented a qualitative exploratory approach, based on the application of a questionnaire to check the causes of the problem. The results highlighted the understanding that the school community has about the role of the
\end{abstract}


principal/manager within the system within it, but this process is not fully implemented or consolidated, causing confusion with the principal/manager's profile in the educational environment. However, the participation of the school community in the implementation of democratic management plays a role of extreme relevance and importance, as pointed out by the research, even, it is often overlooked by the school group, which still today describes the principal/manager as an authoritarian leader, with some skills that can emphasize knowing how to listen and the ability to dialogue, especially encouraging school participation in school context.

Keywords: Participation, leadership, school environment, knowledge.

Submetido: 04/10/2019

Aceito: 20/11/2019

Publicado: 31/12/2019

\section{INTRODUÇÃO}

Nos últimos anos o Brasil vem passando por um processo de redemocratização intenso, o qual se iniciou pelos meados de 1980 e impactou diretamente na educação do país, tornando - o como uma república democrática.

O reflexo dessa ação na educação trouxe entre outros acontecimentos, a gestão democrática, lançando como um grande desafio aos gestores e a comunidade escolar, designando elaborar leis a realidade, como podemos evidenciar os documentos oficiais como a Constituição Federal, Lei de Diretrizes e Bases da Educação Nacional (LDB) e o Plano Nacional de Educação (PNE) (ADRIÃO; CAMARGO, 2001; OLIVEIRA, 2016; DA SILVA; MIRANDA, 2019).

Estudos reportados por Valerien (1993), Gadotti (2001), Libâneo (2004), Paro (2006), Luck (2009), Fonseca (2014), Lima (2014), Paro (2012) e Padilha (2018) enfatizam exatamente em refletir sobre as bases da gestão democrática e suas condições de existência. Os autores afirmam que na prática ainda perdura certo resquício de autoritarismo no ambiente escolar, onde a participação não é plena e os mecanismos democráticos carecem de aperfeiçoamento.

A pesquisa vai ao encontro a essa realidade, confirmando e evidenciando o papel do gestor nesse processo, destacando a problemática do presente estudo em ainda hoje o grupo escolar é referenciado por possuir um processo de gestão de autoritária, sem habilidades entre outros fatores de realização uma gestão de forma democrática (PARO, 2007). Nesse contexto, Paro (2006) chama a atenção para democracia plena, a qual pode ocorrer somente quando existirem pessoas democráticas para exercê-la. A gestão democrática, de forma e norma legal, pode e deve ser aplicado nas escolas, nesse sentido, este estudo visa trazer a resposta com relação ao perfil do diretor/gestor necessário para que a gestão democrática possa ser implantada (CARVALHO, COSTA; ALEXANDRE, 2017; PADILHA, 2018).

O perfil do gestor é de extrema importância, pois destaca coibir ou fomentar a democracia, permitindo a participação não apenas no processo democrático, mas também nas decisões, levando a escola alcançar seus objetivos com a participação de todos. A gestão escolar não deve existir para fins de controle do trabalho, como é apresentado no sistema capitalista, mas como forma de potencializar e aglutinar todas as forças, levando a escola ao sucesso almejado (PARO, 2012). 
Nessa conjuntura, mesmo que a legislação tenha adjetivado a gestão escolar como democrática, ela jamais será, se o gestor não possuir um perfil adequado para exercê-la no seio da comunidade escolar (FONSECA, 2014). Entretanto estudar a gestão escolar democrática e desprezar tanto o perfil como papel do gestor, como o fator humano, a qual é fundamental nas relações sociais, trazendo profundas implicações para as instituições, inclusive educacionais (NASCIMENTO, 2015; COSTA, 2018).

A fim de responder a problemática, o objetivo desse estudo é analisar a percepção da comunidade escolar quanto ao perfil do diretor/gestor a partir da realidade da gestão democrática, através de uma abordagem qualitativa, descrever o processo de gestão democrática, estabelecendo características individuais e únicas do administrador, como suas relações com os atores que fazem parte desse processo, como professores e a equipe como um todo.

A pesquisa foi realizada em uma escola localizada no médio norte do Mato Grosso, composta de uma equipe gestora de três pessoas: diretor, coordenador e mediador, além do quadro docente com trinta e seis professores. O questionário foi composto de questões abertas e fechadas e entregues de forma presencial entre os meses de maio a junho de 2017.

\section{REFERENCIAL TEÓRICO}

\section{Conceituando Gestão}

Essa conceituação é necessária, pois, é possível que a gestão/administração possa ser colocada a serviço de objetivos autoritários, a qual considera que brasileiro, passou e esta passando por um processo de experimentação de mudança histórica, conservando os resquícios de uma mentalidade autoritária em relação ao âmbito da gestão.

De acordo com Paro (2012), a administração vista de forma geral, abstraída de seus determinantes sociais, históricos e contornos capitalistas, podendo ser entendida como o uso racional de recursos, a fim de alcançar fins determinados. Os recursos devem ser moldados e adequados aos objetivos que se almeja, usando os recursos de forma inteligente e definindo as implicações apresentadas (PARO, 2007). Além disso, uma administração é capaz de utilizar os recursos com menor dispêndio e maior brevidade possível na execução, sendo chamada esta faceta da administração de dimensão econômica (FONSECA, 2014; NASCIMENTO, 2015; COSTA, 2018).

Outro aspecto apontado e de extrema relevância é no que se refere a administração de forma e esforço não individual, mas coletivo, onde o aspecto da coletividade e do esforço humano se denomina coordenação (PARO, 2009). Esse fato é explicito por Paro (2012), onde a coordenação está no interior do processo racional da organização do esforço humano, podendo, portanto, dimensionar ao que diz respeito às relações dos homens entre si, e não necessariamente da relação homem/natureza, como encontrado na literatura na área de administração (LIMA, 2014; PADILHA, 2018; DA SILVA; MIRANDA, 2019).

Desse modo conjugam-se os elementos materiais e conceptuais ao esforço humano coletivo para o alcance de determinado fim, onde o fim desejado tem determinantes sociais, de modo que a administração pode constituir-se instrumento de conservação, quanto de transformação social. Enquanto a administração é apresentada de forma instrumental, como administração escolar, este num contexto geral, deve 
voltar-se a transformação social, uma vez que o objetivo da escola é o aprendizado dos alunos, portanto, mudança, e não manutenção do status quo.

Considerando a aprendizagem dos alunos como fim desejo, a gestão democrática irá mobilizar esforço humano coletivo e os elementos materiais e conceptuais para alcançá-lo (LUCKESI, 2007). As ações administrativas, logo, levam em consideração os fins almejados da instituição, no fato que a escola, deve considerar o estilo de direção, o grau de participação e o comprometimento de seus profissionais, além da liderança, a participação coletiva, o currículo, a formação de seus professores e a cultura organizacional, sendo fatores que compõem as características organizacionais dessa instituição (LIBÂNEO, 2004; CURY, 2007; OLIVEIRA, 2010)

De acordo com Lück (2009a), o termo gestão não é sinônimo de administração. Para a autora, inclusive a diferença é radical, onde aquilo que se propunha sob a denominação de administração é muito menor, para aquilo que se espera e atribui a gestão.

Não se pode realizar uma maquiagem modernizadora, posto que a ideia de gestão educacional engloba questões dinâmicas da educação: dimensão política e social, cidadania, etc (GRACINDO, 2012). Diante dessa complexidade, as organizações e a concorrência de múltiplos interesses sociais dentro delas, se manifestam, evidenciando que não é possível, que tais organizações sejam administradas pelos antigos paradigmas e enfoques conceituais (PARO, 2007).

Desse modo, os paradigmas conceituais da administração são insuficientes, pois estes conduzem a ação de controlar e comandar, típico de uma visão de quem atua de maneira distanciada e cultiva pressupostos tais como um comportamento humano previsível e comportamento controlável, onde fases de crises e incertezas, são evitados e esses problemas jamais são vistos como uma possibilidade e oportunidade de crescimento e ajuste, onde o sucesso alcançado, mantem-se por si só, não sendo necessários novos esforços e manutenção (GADOTTI, 2001; PARO, 2006; LÜCK, 2009a; FONSECA, 2014).

Além disso, o papel do administrador é obter recursos, onde a mudança dos modelos administrativos são apenas adaptações, onde o participante da comunidade escolar aceita aquilo que é imposto a ele, aceitando o modelo pré-estabelecido, e agindo de acordo as regras implementadas e elaboradas pelo administrador (LÜCK, 2009b; PARO, 2012; LIMA, 2014).

Destacando apenas o volume de trabalho e não fazendo o melhor, mas sim o máximo, com isso a objetividade é quem produz os resultados e a técnica causa apenas a melhora do trabalho, se transformando em elemento indispensável para os resultados. Os pressupostos da administração expostos anteriormente são claramente limitados, não funcionais, para estabelecer na instituição um enfoque transformador (PARO, 2007; GRACINDO, 2012; CARVALHO, COSTA; ALEXANDRE, 2017; PADILHA, 2018).

A gestão, conta com a pluralidade, utilizando-se de diferentes dimensões, aparentemente opostas, libertando-se da dicotomia e aglutinando uma diversidade de forças na construção da realidade. (OLIVEIRA, 2016; DA SILVA; MIRANDA, 2019. Assim, nos estudos de Paro (2012) e Lück (2009a), os autores entendem que gestão terá apenas uma natureza de caráter potencialmente transformador.

\section{A Gestão Escolar Adjetivada}

O processo de redemocratização no Brasil, não marcou apenas a vida política e social, marcou também a educação. O período pós-ditatorial, a partir da década de 1980 , 
traz consigo a marca de uma política com preocupações de ordem gerencial, dimensionando o Brasil para a inserção na globalização econômica, produzindo um profundo impacto na gestão e também no planejamento escolar (LÜCK, 2012; FONSECA, 2014).

Em relação a educação, pode se definir como um movimento já consagrado anteriormente, pois em 1988 com o advento da promulgação da Constituição Federal, objetivou a instituição do Estado Democrático, assegurando os direitos sociais e individuais, garantindo assim a educação como um direito e a gestão democrática como uma ferramenta para consecução dos objetivos educacionais (SHIMAMOTO, 2011; TORRES; GARSKE 2008; TAVARES, 2019).

Observamos essa realidade apresentada na Constituição Federal, no seu artigo 205, que assegura "a educação, direito de todos e dever do Estado e da família, será promovida e incentivada com a colaboração da sociedade" (BRASIL, 1988), lançando assim a participação coletiva como base na construção da educação, uma vez que a sociedade é chamada a participação efetiva.

A redação do artigo 205 da Constituição, afirma que os objetivos da educação: o desenvolvimento da pessoa, o preparo para o exercício da cidadania e para o trabalho, serão alcançados com a participação da sociedade (BRASIL, 1988). É relevante constatar, que a Constituição vai muito além, pois ela institui a democracia como base para a construção da educação e adjetiva a própria gestão educacional como democrática, ou seja, a gestão democrática é o modo como vamos alcançar os objetivos da escola. Desse modo a ação do gestor/diretor deverá ser democrática (RICHARDSON, 1999; ROBBINS, JUDGE; SOBRAL, 2010; CÁRIA; LAMBERTDE-ANDRADE, 2016; GHISLENI; COSTA, 2019).

Todos os sistemas de ensino ficam então forçados a implantar o exercício de gestão democrática, não apenas porque a democracia tornou-se base de construção de nossa educação, mas também, porque a mesma Constituição, no inciso VI, artigo 206, declara expressamente que o ensino será ministrado, na forma da lei, pela gestão democrática no ensino público (BRASIL, 1988). Uma vez que a Carta Magna, fez as referidas conceituações do modo como a educação será ministrada e gerida é natural que os demais instrumentos legais sigam suas preceituações.

A concretização do direito à educação se dará de forma democrática, como meio de alcançar seus fins e, portanto, também como gestão democrática, consagradas pela Constituição e afirmadas também através da Lei de Diretrizes e Bases da Educação Nacional LDB - (Lei $\mathrm{n}^{\circ}$ 9.394, de 20 de dezembro de 1996), no seu inciso VIII do artigo $3^{\circ}$, que afirma que a gestão do ensino público será democrática, na forma da lei, e que os sistemas de ensino deverão criar suas legislações próprias para sua implementação (BRASIL, 1996).

O processo histórico de redemocratização do país e consequentemente da educação, além disso, deu - se aos educadores, a possibilidade de debater em fóruns nacionais dedicados a pensar um plano de metas para educação. As propostas dos Congressos Nacionais de Educação (CONEDs) foram incorporadas na construção do futuro ao Plano Nacional de Educação (PNE) (FONSECA, 2014; CÁRIA; LAMBERTDE-ANDRADE, 2016; GHISLENI; COSTA, 2019; TAVARES, 2019).

O Plano Nacional de Educação (PNE) em vigor (2014-2024) possui dez diretrizes, sendo que a sexta diretriz esboça a necessidade da promoção da gestão democrática no ensino público. Através do artigo nono do Plano Nacional de Educação (PNE), fica definido que a aprovação de leis específicas para os sistemas de ensino, para 
disciplinar a gestão democrática, é de responsabilidades dos entes federativos, que terão prazo de dois anos para tal execução. O Plano Nacional de Educação (PNE) busca não apenas a implantação da gestão democrática, mas também institui metas de qualidade e de avaliação das condições dessa gestão (BRASIL, 2014).

A partir desse momento, os sistemas de ensino devem organizar-se para alcançar os fins prescritos nos documentos legais, ou seja, esses sistemas de ensino em suas dimensões estaduais e municipais preparam seus ordenamentos jurídicos, que visam a organização prática e cotidiana da escola (SHIMAMOTO, 2011; CÁRIA; LAMBERTDE-ANDRADE, 2016).

Podemos tomar como, por exemplo, a Secretaria de Educação do Estado de São Paulo (SEE-SP) que através da Resolução SE No 70/2010, busca caracterizar as dimensões da gestão democráticas como: Gestão Pedagógica; Gestão dos Recursos Humanos; Gestão Participativa; Gestão dos Recursos Físicos e Financeiros; Gestão de Resultados Educacionais do Ensino e da Aprendizagem.

Inclusive a Secretaria de Educação do Estado de São Paulo (SEE-SP) entende que a gestão pedagógica, envolve todo o trabalho pedagógico da escola, tais como, implementação do currículo, práticas pedagógicas inovadoras, acompanhamento dos níveis de aprendizagem dos alunos que leve em conta os resultados de avaliação, atuação dos professores articulada com a Proposta Pedagógica e com as necessidades de melhoria do rendimento escolar, acompanhamento dos processos de recuperação dos alunos, ou seja, isso significa o acompanhamento cotidiano das questões da sala de aula: Proposta Pedagógica, currículo, planejamento de aula, avaliação, etc. (PARO, 2006; GOMES, 2015).

Gestão de pessoas é aquela que envolve todos os processos que visam ao envolvimento e compromisso de todos (professores, funcionários, pais e alunos) com a Proposta Pedagógica da escola, além de envolver também a formação e $o$ desenvolvimento pessoal de seus integrantes (FAVARIN; DA ROCHA, 2015; CÁRIA; LAMBERT-DE-ANDRADE，2016; VIEIRA; VIDAL，2015; LÜCK, 2017; SILVA, 2019).

Gestão dos resultados por sua vez avalia os resultados do desempenho da escola e de seus alunos, professores e funcionários; tem a função de assegurar o acesso, a permanência e o sucesso escolar dos alunos, e monitora e acompanha os seus resultados, bem como fatores associados ao fluxo escolar, tais como: taxas de abandono, evasão, aprovação e reprovação dos alunos (LÜCK, 2017; MACHADO, 2017).

Gestão de infraestrutura (recursos didáticos, materiais físicos e financeiros) refere-se a processos e práticas eficientes e eficazes de gestão dos serviços de apoio e de recursos físicos e financeiros, que envolvem toda a infraestrutura necessária para o desenvolvimento do processo de ensino e aprendizagem (FONSECA, 2014; CÁRIA; LAMBERT-DE-ANDRADE, 2016; LÜCK, 2017).

Gestão participativa irá efetivar os processos de participação coletiva, no estabelecimento de articulações e parcerias, na integração da escola com a comunidade, implicando em discutir, elaborar e acompanhar as ações desenvolvidas na escola, articuladas com a Proposta Pedagógica, além de envolver a participação dos pais, alunos e a atuação de órgãos colegiados dos Conselhos Escolares, Associações de Pais e Mestres, Grêmios Estudantis e outros. Contudo, reconhece o papel do gestor como aquele que persegue a oferta do ensino de qualidade, construindo um espaço produtivo que permita a convivência social e coletiva mais humana e construtiva (SEE-SP, 2010). 
A mesma secretaria também estabelece que as escolas devam ter um Plano de Gestão, definida na legislação estadual em Normas Regimentais Básicas para as Escolas Estaduais - 201, Do Plano de Gestão da Escola - Título II - Capítulo V, que estabelece no Artigo 29, que esse Plano de Gestão é um documento coletivo que define o perfil da escola, construindo sua identidade, contemplando as intenções de todos os envolvidos, norteando o gerenciamento das ações intraescolares e efetivando a Proposta Pedagógica (SEE-SP, 2010). De modo geral a gestão democrática é entendida como aquela que organiza a participação da comunidade, cria conselhos consultivos e deliberativos, além de transparente e competente na utilização dos recursos financeiros repassados diretamente às escolas.

\section{Gestão escolar democrática}

Uma vez estabelecido, por força de lei, que a gestão escolar deverá ser democrática, precisamos entender seu significado, ou seja, devemos olharmos a sociedade em que vivemos, com contornos democráticos, nota-se que precisamos adequar os padrões da escola para abrigar esse novo contexto e preparar os que dela vão sair para viver de acordo com a realidade do mundo de hoje.

Não podemos definir a escola como um espaço aonde a clientela chega e sai sem ao menos saber os objetivos de ter passado por ela. A sociedade hoje pede mais que isso, além de trazer para dentro da escola um público com culturas e hábitos diversificados tornando assim a escola um lugar de troca de conhecimento e experiência para todos que nela estão inseridos. Para tanto se faz necessário um novo padrão para definir a direção desta instituição, chegando ao entendimento de que esta direção precisaria ser mais que um aprofundamento burocrático como era o que vinha sendo executado pelos que a compunham (SANTOS, 2001; PARO, 2007; DE SOUZA, 2009).

Gestão democrática no contexto educacional pontua a participação consciente das pessoas nas decisões na orientação e planejamento do trabalho escolar (ADRIÃO; CAMARGO, 2001). Segundo Lück (2009), essa foi uma mudança de paradigma, onde aquilo que era atribuição e responsabilidade apenas das pessoas que trabalham na educação agora considera a participação de toda a comunidade, pois o conceito de gestão escolar está ligada ao fortalecimento do processo pedagógico com caráter democrático, à participação responsável de toda a comunidade escolar nas decisões necessárias e na sua efetivação através de um compromisso coletivo para o alcance de resultados educacionais cada vez mais efetivos e significativos (DOURADO, 2016; VIEIRA, 2017).

Sendo assim, para o autor, o movimento pela gestão escolar democrática reconhece a necessidade de unir essas mudanças estruturais e de procedimentos com ênfase no aprimoramento da escola, por meio de um projeto pedagógico segundo Diretrizes, Metas e Estratégias do PNE (BRASIL, 2014). Portanto, deve-se considerar que na gestão escolar democrática segundo Lima (2014)

Decisão emerge como uma dimensão central da gestão democrática das escolas, não apenas pelos fenómenos de participação ativa que são típicos dos processos de organização e mobilização democráticas, mas também porque a participação verdadeira exige muito mais do que o acesso à informação e o direito a ser informado, a publicidade democrática dos atos, as propostas e sugestões, as auscultações e outros processos eventualmente despojados de poder de decisão, que Maurício Tragtenberg (1989) designou de "participacionismo". Pelo 
contrário, só o poder de decidir confere pleno sentido às práticas de governo democrático das escolas, rompendo com encenações participativas, com rituais, processos e métodos formalmente democráticos, mas a que falta substantividade democrática (LIMA, 2014, p. 1072).

Além da participação nas decisões como aspecto fundamental da gestão democrática, Lima (2014) insiste que o processo democrático de gerir, não está limitado ao cumprimento das próprias regras do processo democráticas, pois democracia pressupõe autonomia, ou seja, a possibilidade, mesmo que considerados os limites tanto prático como constitucional/jurídico, de construir as próprias regras, mesmo em coautoria com outras instâncias superiores, não inteiramente subordinados às regras dos outros, a heteronomia (LIMA, 2014).

Portando, não se aceita assim, nenhum tipo de pseudoparticipação, pois participar é decidir, e co-decidir, contudo, a democracia, é o poder de decidir, com participação ativa juntamente com os outros nos processos de decisão, que é o âmago da democracia. Se não for assim é impossível conceber uma gestão democráticas nas escolas (LIMA, 2014). Não é suficiente possuir uma lei de gestão democrática que oferece autonomia em todos os âmbitos da vida da escola, se a comunidade escolar de modo geral, desconhecer o significado político da autonomia, a qual não é um presente, mas sim uma construção ininterrupta, particular e coletiva. É um processo que se faz no cotidiano (GADOTTI, 2001; OLIVEIRA; RIBEIRO, 2015).

Embora a legislação vigente adjetive a gestão como democrática, muitas vezes é pautada pelo tradicionalismo e conservadorismo. Realizar um trabalho participativo, autônomo e democrático, que envolva toda a comunidade escolar, possibilitará o rompimento da atitude autoritária que permeia a escola, proporcionando uma reflexão sobre o papel do gestor, levando a busca da tão sonhada escola de qualidade.

De acordo com Paro (2012), a administração tipicamente capitalista é conservadora, pois está voltada para mecanismos gerenciais de controle do trabalhador, preocupa-se em controlar o trabalho alheio, ignorando os aspectos da dimensão técnica, capaz de auxiliar no alcance dos resultados desejados, ou seja, é capaz de identificar em cotidiano uma escola tornando - se engessada, burocratizada, afastada da realidade e incapaz de solucionar problemas editando normas de controle e alijando a capacitação cultural das classes trabalhadoras.

Um exemplo, dessa típica administração capitalista no seio da escola, é a divisão pormenorizada do trabalho, sob justificativa de melhor aproveitamento dos recursos escassos, reordenação do currículo, melhor planejamento das atividades didáticas, acompanhamento do trabalho docente, por supervisores, que na prática, segundo o autor, produz apenas uma excessiva rotinização e burocratização da escola.

Desse modo o ambiente escolar, será de trabalho individual, onde cada um realiza sua função, não favorecendo o compartilhamento de experiências e construção de saberes, sem interpenetração de áreas, pois os espaços são delimitados. Sendo assim, é preciso estabelecer uma nova filosofia de gestão que rompa com os paradigmas tradicionais e questione o modelo de gestão escolar que vem sendo praticado e adotado em algumas escolas brasileiras, de acordo com Paro (2006),

Há pessoas trabalhando na escola, especialmente em postos de direção, que se dizem democratas apenas porque são "liberais" com alunos, professores, funcionários ou pais, porque lhes "dão abertura" ou "permitem" que tomem 
parte desta ou daquela decisão. Mas o que esse discurso parece não conseguir encobrir totalmente é que, se a participação depende de alguém que dá abertura ou permite sua manifestação, então a prática em que tem lugar essa participação não pode ser considerada democrática, pois democracia não se concede, se realiza: não pode existir "ditador democrático" (PARO, 2006, pp. 18-19).

Conforme afirma Paro (2006), a democracia plena pode existir quando também existem indivíduos democráticos para exercê-la, assim, o papel do gestor é fundamental no direcionamento do trabalho participativo, onde será impossível um diretor/gestor autoritário implantar um processo de gestão democrática. Gestão democrática, mais que um meio, será um pressuposto definidor, que clama e pede um perfil de gestor adequado, sem resquícios totalitário e capaz de desenvolver um trabalho coletivo que engloba toda a comunidade educacional.

Mesmo que o trabalho do gestor envolva ações de caráter administrativo, insiste Lück (2009), sua ação também deve estar voltada em elaborar conjuntamente com a comunidade escolar o projeto político-pedagógico, cuidar das relações interpessoais da organização, liderar, entender que a mudança dos processos pedagógicos traz consigo relações sociais diferenciadas, e que a sinergia e competência suplantam a necessidade de insumos ou recursos para o sucesso da organização. Desse modo, a gestão será meio para transformar a escola, em uma organização democrática, que demanda a participação ativa da sociedade, nas tomadas de decisões e no planejamento participativo.

\section{PROCEDIMENTOS METODOLÓGICOS}

Primeiramente para concretização desse estudo, foi realizada uma avaliação literária geral sobre o tema proposto, pesquisando as informações, com objetivo checar as causas do problema, descrevendo e explicando o motivo pelo que um fato ocorre, estabelecendo critérios de avaliação, evidenciando acerca dos critérios de avaliação referente às novas normas de ensino e contextualizando sobre a democratização da educação, a partir do conteúdo do atual Plano Nacional de Educação (PNE, 2019), do direito social inalienável proposto na Constituição Federal de 1988 (CF/88) (BRASIL, 1988) e da importância do Sistema Nacional de Educação (SNE).

Para os procedimentos técnicos refere - se a uma pesquisa de caso com aplicação de um questionário que visa estudar a percepção que um grupo de pessoas tem sobre um determinado tema, possibilitando uma investigação minuciosa sobre os fatores que o levam a ocorrer, possibilitando encontrar soluções para problemas apresentados. Permitindo assim analisar, entender e descrever certas minucias do comportamento das pessoas, de maneira mais intensa (RICHARDSON, 1999).

A escolha do método transcorreu por ser consideravelmente a melhor forma de apresentar os resultados da pesquisa com o intuito de destacar em um sentido geral, a questão da gestão democrática escolar na sua expressão geral, buscando evidenciar o conceito sem condicionamentos sociais, entendendo o perfil do administrador.

A escolha da escola foi de forma pragmática, em função do facilitado acesso ao corpo docente, uma vez que o pesquisador é professor efetivo, locado na instituição pesquisada. Participando professores do período da manhã e da tarde, ensino médio e fundamental II, além dos integrantes da equipe gestora, totalizando um grupo de 25 
pessoas. Sendo entregue um questionário composto de seis questões, sendo destas três abertas discursivas e três fechadas.

A natureza das questões fechadas possibilita delimitar o escopo das respostas, além de serem questões objetivas, as respostas serão limitadas. Além disso, foi considerado a dificuldade de análise dos dados e de tabulação posterior, optando-se pelo formato, para manter a isenção e a influência na resposta dos entrevistados. Referindose a certa da implantação da gestão democrática em escolas estaduais, o papel do diretor e as dimensões da gestão escolar (considerando seu aspecto democrático). As questões abertas mencionam as ações que poderiam ser realizadas a respeito da gestão ser mais democrática, além do papel do diretor e o melhor perfil administrativo.

As perguntas foram construídas com o objetivo de verificar a percepção dos docentes quanto a implantação da gestão democrática, e também constatar a importância e o perfil do gestor na democratização do processo, verificando as áreas da gestão com maior dificuldades de implantação. No que concerne as áreas da gestão foi empregada a definição contida na Resolução SE No 70/2010, da Secretaria da Educação do Estado de São Paulo: Gestão Pedagógica; Gestão dos Recursos Humanos; Gestão Participativa; Gestão dos Recursos Físicos e Financeiros e Gestão de Resultados Educacionais do Ensino e da Aprendizagem.

A participação foi de forma anônima, onde os entrevistados forneceram informações relevantes, que permitiram agrupá-los em áreas específicas, como: semelhanças, percepção, formação, idade, categoria, entre outros. Facilitando a compreensão e entendimento das questões, além de permitir tabular todas as informações, verificando possíveis discrepâncias e percepção entre os grupos.

\section{RESULTADOS E DISCUSSÃO}

\section{A percepção da comunidade escolar sobre a implantação da gestão democrática}

As atribuições nas dimensões econômica-pedagógica-coletiva, que unem os conceitos de administração geral, irão gerar um perfil de gestor, capaz de lidar com a realidade dinâmica da escola pretendida, dando origem assim, a uma escola viva, capaz de exercer um papel transformador, ou seja, as dimensões da administração geral apontam para as áreas de atuação do gestor, reforçando ainda mais a necessidade de uma prática democrática em suas ações (Tabela 1). Os princípios da administração geral, aplicados a escola que queremos, geram tanto o perfil do gestor, bem como suas áreas de atuação.

Tabela 1. Sumario da relação das dimensões da administração geral com as dimensões da gestão escolar democrática.

\begin{tabular}{ll}
\hline Administração Geral & Gestão escolar democrática (áreas de atuação do gestor) \\
\hline Dimensão econômica & Gestão dos Recursos Físicos e Financeiros \\
\hline Dimensão pedagógica & $\begin{array}{l}\text { Gestão Pedagógica } \\
\text { Gestão de Resultados Educacionais do Ensino e da Aprendizagem }\end{array}$ \\
\hline Dimensão coletiva & $\begin{array}{l}\text { Gestão dos Recursos Humanos } \\
\text { Gestão Participativa }\end{array}$ \\
\hline
\end{tabular}

Fonte: Elaborada pelos autores (2018), com base em Paro (2012), Lück (2009) e SEE-SP (2010)

Finalmente, a práxis do trabalho gestor na escola, irá exigir um perfil adequado: um gestor democrático com ações democráticas. A prática cotidiana a percepção da 
realidade democrática, mesmo bem definida e estabelecida na legislação, na prática pode ser bem diferente. Restando ainda ser explorada e perseguida, principalmente quando relacionamos e questionamos se a gestão democrática implantada nas escolas estaduais, $80 \%$ responderam que não, $5 \%$ que sim e $15 \%$ que está implantada parcialmente. Avaliando as áreas da gestão que apresentam maior dificuldade para implantação, levando em consideração seu aspecto democrático (Figura 1).

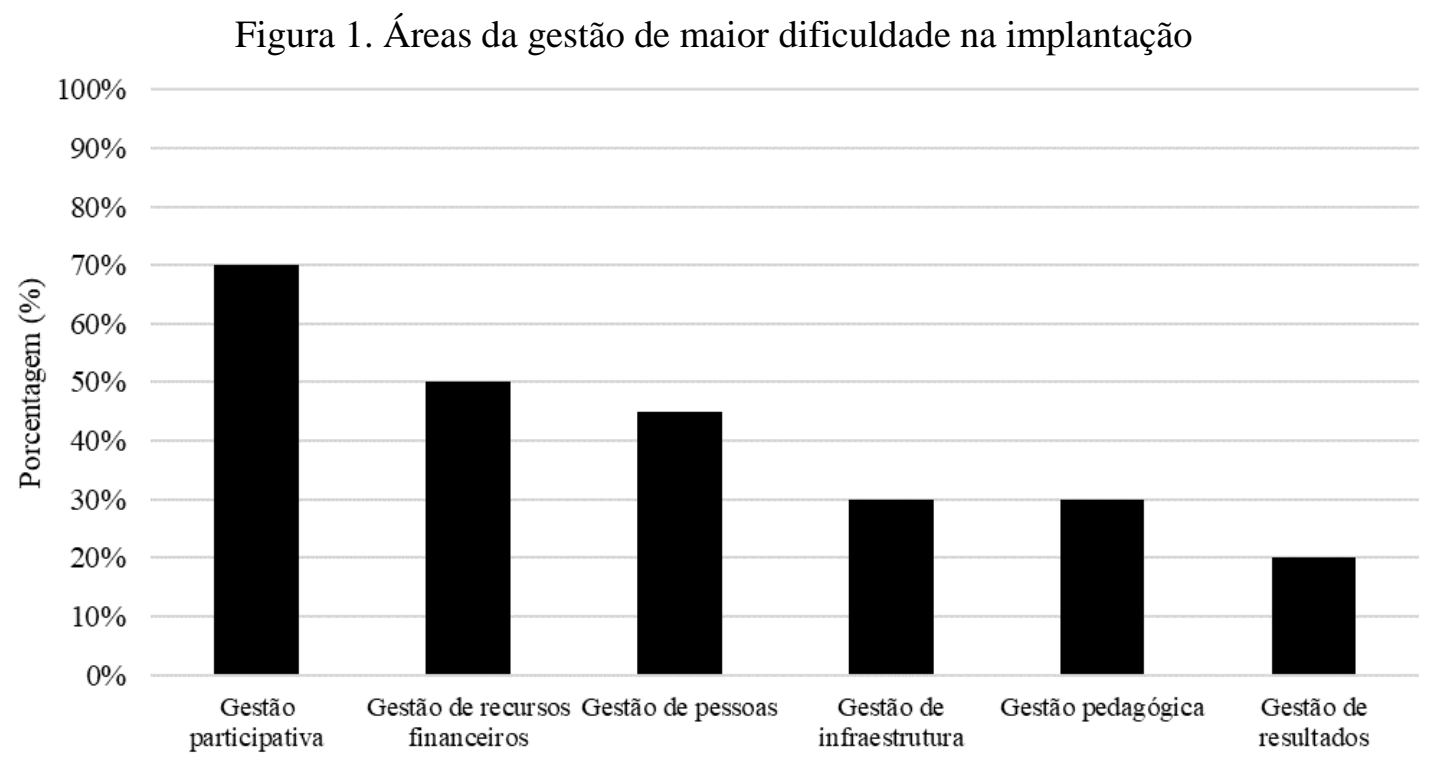

Fonte: Resultados originais da pesquisa (2018)

Das avaliações, $70 \%$ dos participantes apontaram que a gestão participativa é a de maior dificuldade, seguidas de 50\% para gestão de recursos financeiros e $45 \%$ para a gestão de pessoas. Como os pesquisados, apontaram mais de uma área, os percentuais da cada área devem ser analisados a partir da totalidade dos participantes, ou seja, dos $100 \%$, que responderam à questão, $70 \%$ apontou "gestão participativa", como era possível assinalar mais de uma opção, "gestão de recursos" aparece com 50\% e "gestão participativa" 45\%. Assim o percentual do campo "total de pesquisados", não será $100 \%$.

A liberdade do participante da pesquisa em assinalar mais de uma opção, foi importante, no sentido de foi possível contatar que as áreas da gestão, que exige maior participação da comunidade escolar, foram apontadas como as mais difíceis de implantar. Levando em consideração que na escola exista algum tipo de participação, mesmo que mínima, e que a gestão de recursos e de pessoas é inerente a ela como organização, conclui-se que elas existem de forma precária, ou de forma autoritária.

A maioria dos participantes da entrevista (Tabela 2) entende que as ações para escola ser mais democrática estão nas áreas da gestão participativa e recursos humanos deveriam englobar ações como a elaboração do PPP em conjunto com a comunidade escolar, os professores deveriam ser ouvidos quanto as questões relacionadas a educação através de debates e esclarecimento dos resultados, a comunidade escolar deveria ser ouvida e participativa junto na tomada de decisões dentro da escola, assim melhoraria o ambiente escolar. 
Tabela 2. Ações que poderiam fazer a gestão ser mais democrática

\begin{tabular}{|c|c|c|}
\hline $\begin{array}{l}\text { Administração } \\
\text { Geral }\end{array}$ & $\begin{array}{l}\text { Gestão escolar democrática } \\
\text { (áreas de atuação do gestor) }\end{array}$ & $\begin{array}{l}\text { Ações para a escola ser mais } \\
\text { democrática } \\
\text { (resumo das opiniões) }\end{array}$ \\
\hline $\begin{array}{l}\text { Dimensão } \\
\text { Econômica }\end{array}$ & $\begin{array}{l}\text { - Gestão dos Recursos Físicos e } \\
\text { Financeiros }\end{array}$ & - estrutura, recursos financeiros \\
\hline $\begin{array}{l}\text { Dimensão } \\
\text { Pedagógica }\end{array}$ & $\begin{array}{l}\text { - Gestão Pedagógica } \\
\text { - Gestão de Resultados } \\
\text { Educacionais do Ensino e da } \\
\text { Aprendizagem }\end{array}$ & $\begin{array}{l}\text { - elaborar o PPP em conjunto com a } \\
\text { comunidade escolar } \\
\text { - professores serem ouvidos quanto as } \\
\text { questões relacionadas a educação } \\
\text { - bem como o esclarecimento dos } \\
\text { resultados }\end{array}$ \\
\hline $\begin{array}{l}\text { Dimensão } \\
\text { Coletiva }\end{array}$ & $\begin{array}{l}\text { - Gestão Participativa } \\
\text { - Gestão dos Recursos Humanos }\end{array}$ & $\begin{array}{l}\text { - participação e dialogo com } \\
\text { comunidade escolar } \\
\text { - melhora do ambiente escolar } \\
\text { - ação efetiva do conselho, da APM e } \\
\text { do grêmio dentro da escola } \\
\text { - participação nas decisões }\end{array}$ \\
\hline
\end{tabular}

Fonte: Resultados originais da pesquisa (2018)

Para os participantes, o maior envolvimento e diálogo com a comunidade escolar, torna a escola mais democrática, todavia, se observa que a maioria entende as limitações dos gestores em providenciar recursos financeiros e matérias, mas esperam mais dialogo e maior participação nas decisões. A percepção da comunidade escolar quanto ao perfil necessário de diretor para implantação da gestão escolar democrática. Com relação as que deveriam ser tomadas para uma escola mais democrática estão nas apresentadas na Figura 2.

Figura 2. Porcentagem de ações que poderiam fazer a gestão ser mais democrática

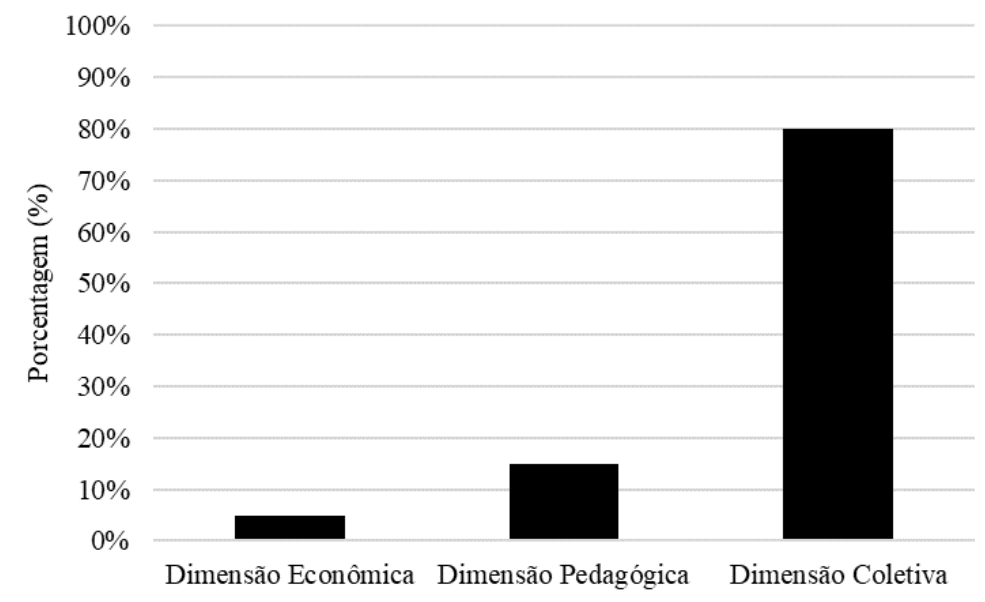

Fonte: Resultados originais da pesquisa (2018)

Podemos observar que $80 \%$ referem - se a uma dimensão mais coletiva, seguida de $15 \%$ com ações de dimensão pedagógica e 5\% de dimensão econômica, com atuação nas áreas de gestão dos recursos físicos e financeiros, pedagógica e nos resultados educacionais do ensino e da aprendizagem, respectivamente. 
Para esboçar um perfil do gestor, levamos em consideração conceitos já elaborados neste estudo. Podemos sumariar que a administração é a utilização capaz dos recursos - dimensão econômica, que a administração leva em conta os fins institucionais, fala da dimensão pedagógica, e por fim, que a administração deva mobilizar os esforços humanos - dimensão coletiva. Para Valérien (1993), o diretor precisa cada vez mais levar em conta a evolução da ideia de democracia, que leva a comunidade escolar à maior participação com natural implicação sobre as decisões.

Por essa razão, o diretor que também pode ser chamado de gestor escolar ou ainda líder formal, terá como uma das características centrais do seu trabalho, o esforço contínuo de organizar os trabalhos escolares envolvendo os diferentes segmentos representativos da escola-professor, funcionários, alunos e comunidade, com isso a dimensão do gestor, terá além do papel de educador, como de buscar e alcançar os objetivos educacionais da escola, do saber e da aprendizagem dos alunos, apontamos assim, as características fundamentais do perfil do diretor, como líder. Essa característica foi a segunda mais apontada por 30\%, dos participantes (Figura 3).

Figura 3. O perfil do diretor para que a gestão seja democrática.

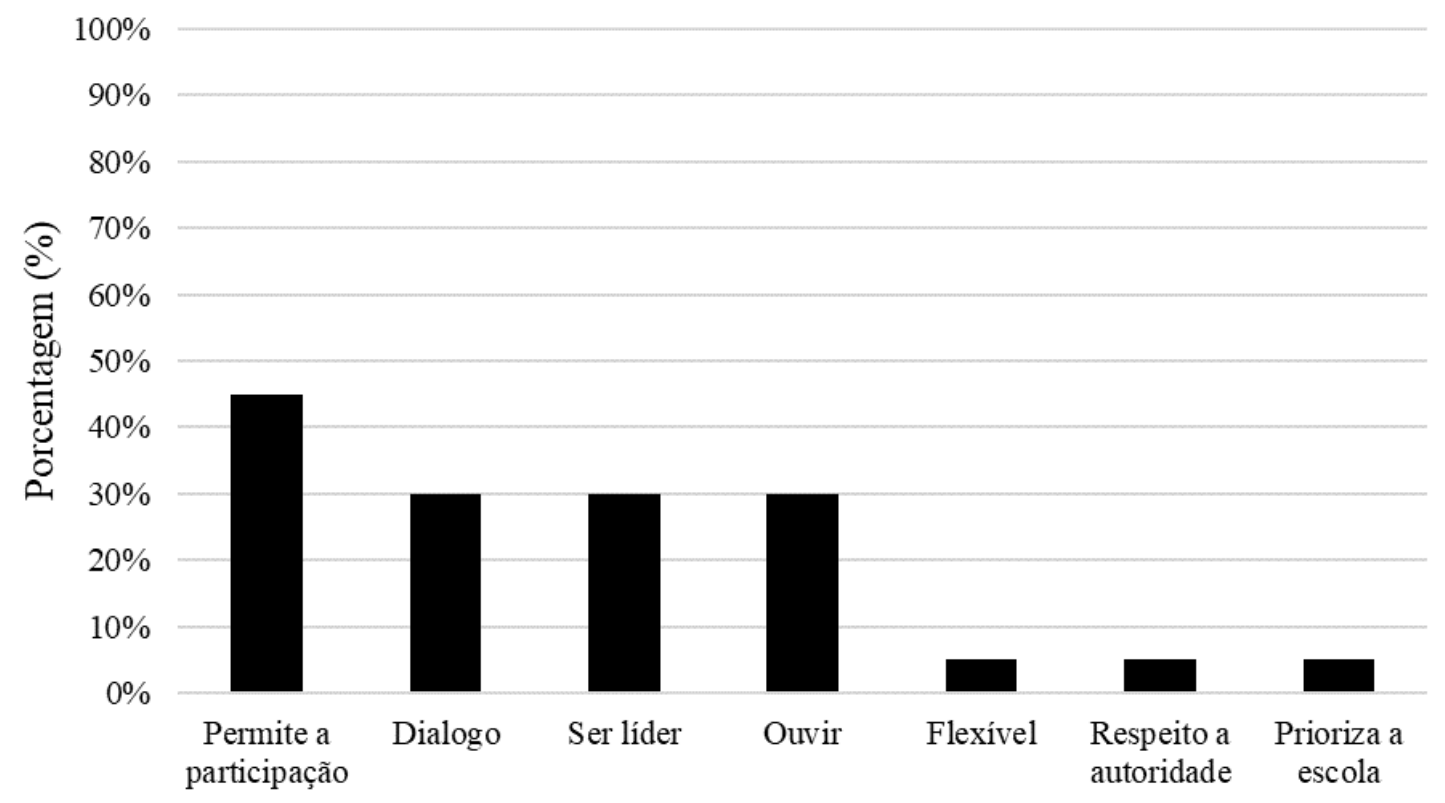

Fonte: Resultados originais da pesquisa (2018).

Podemos observar que entre as características do diretor, destacamos $45 \%$ a permissão da participação, 30\% dialogo, 30\% liderança, 30\% ter voz, 5\% ser flexível, $5 \%$ respeito a autoridade e $5 \%$ priorização da escola. Ser líder não é ser gerente, no sentido de controlar as ações dos trabalhadores, conforme os princípios da administração capitalista (PARO, 2012), é muito mais do que isto, é possuir uma visão global da escola como uma instituição social e que sob sua liderança promove a sinergia pedagógica, voltada para a dinamização e coordenação do processo co-participativo, capaz de atender as demandas educacionais (LÜCK, 2009a; CABRAL; SOUSA; DO NASCIMENTO, 2015; LOPES, OLIVEIRA; SILVA, 2016).

Para Becker (2017) a gestão escolar deve ser participativa, oportunizando a democracia com direito a opinião e decisão, segundo o autor 
Torna-se, assim, aceitável compreender que o trabalho dos gestores escolares se assenta sobre sua capacidade de liderança, isto é, da capacidade de influenciar a atuação de pessoas para o trabalho, a aprendizagem e a construção de conhecimentos. A gestão se constitui em processo de mobilização e organização do talento humano para atuar de forma compartilhada na promoção dos objetivos educacionais. Contudo, um dos principais empecilhos na efetivação da gestão escolar participativa é a resistência à mudança, mesmo as almejadas, por parte da comunidade escolar (pais, alunos, professores e demais funcionários) que, por vezes, omitem-se e não colaboram (BECKER, 2017, p. 395).

Liderança é o processo de encorajar os outros a trabalharem positivamente na consecução dos objetivos, como o fator humano, que ajuda um grupo a identificar para onde ele está indo e assim a motivar-se em direção ao objetivo. Uma organização sem liderança seria somente uma confusão de pessoas e máquinas assim como uma orquestra sem maestro seria somente músicos e instrumentos. A orquestra e todas as outras organizações requerem liderança para se desenvolver ao máximo (CURY, 2007; LÜCK, 2012; DE SOUZA; DE OLIVEIRA; CARVALHO, 2017).

De acordo com Maximiano (1995), a liderança, considerada atributo da pessoa, "é a capacidade pessoal, inerente ao indivíduo, de fazer obedecer, de influenciar ou orientar o comportamento alheio". Segundo Lück (2008), as três principais linhas teóricas sobre liderança são a teoria dos traços de personalidade, que analisa a efetividade da liderança a partir de um conjunto de características especiais de um líder; teoria dos estilos de liderança, que se assenta sobre a ênfase dada à distribuição de poder; a teoria situacional, que explica a liderança dos processos e fatores contingências e a dinâmica da cultura organizacional dos contextos onde a liderança se expressa (BECHER, 2017).

As características do gestor, nos dias atuais, não estão agregadas apenas nos traços pessoais ou técnicos, mas naquelas características que são aprimoradas no decorrer do dia a dia, das ações que são enfrentadas, das dificuldades que são superadas. Esses e tantos outros aspectos transformam, modificam o modo de trabalho do gestor como líder (DE SOUZA; DE OLIVEIRA; CARVALHO, 2017).

Quando se tem um gestor líder com postura positiva em suas ações, isso normalmente contagia a equipe que se torna motivada, sem medo de mudanças e desafios, onde o gestor dessa maneira, propícia a busca da satisfação pessoal pelo profissional que ali atua. Ser líder não é ser gerente que executa tarefas, controla recursos, administra uma estrutura, etc. Embora não negamos que seja necessário o gestor possuir habilidades técnicas, que é exatamente a capacidade de aplicar conhecimentos específicos da sua área de atuação, contudo o gestor escolar necessita de habilidades especificas, tais como: conhecimentos pedagógicos, legais, habilidades de gerir recursos e infraestrutura etc.

Entretanto, não podemos ignorar a grande importância das habilidades humanas, que é exatamente a capacidade de trabalhar com pessoas e equipes, tornando-as participantes, responsáveis, compreendendo-as e motivando-a (ROBBINS et al., 2010).

Becker (2017) destaca o papel da liderança dentro do contexto organizacional escolar como articulador da orientação direção desejada, interpretando sentimentos e expectativas do dentro de um contexto cultural. Ritter (1994 apud BERGAMINI, 2005, p. 132), menciona que o líder eficaz combina quatro talentos, a saber 
1. talento cognitivo: capacidade de interpretar o mundo para compreender os objetivos pela organização;

2. talento social e político: capacidade de compreender o sistema social que é a organização e a capacidade de influir sobre sua evolução por meio de decisões que dizem respeito às estruturas e regras, bem como as particularidades dos indivíduos do grupo que levem a ser detentor da autoridade formal;

3. talento Intrapsíquico: capacidade de pensar no seu próprio poder e perceber os perigos das suas próprias paixões;

4. talento Ético: capacidade de compreender o poder organizacional; deposita nele a responsabilidade frente ao outro, na medida em que arrasta aqueles que seguem na sua interpretação do mundo e sua ação sobre o social.

Desenvolver relacionamentos interpessoais trará grandes ganhos para o ambiente de trabalho, onde ser bom ouvinte, dialogar sempre, fomentar e permitir a participação, saber entender a necessidade das pessoas e administrar conflitos, fazem parte do portfólio de um bom gestor. Como ele vai realizar sua tarefa através do trabalho de outras pessoas, precisa ter boas habilidades humanas (CURY, 2007; DE SOUZA; DE OLIVEIRA; CARVALHO, 2017). A escola não necessita de gerente, alguém para controlar o trabalho e dividi-lo, ou supervisionar os trabalhadores, mas alguém capaz de caminhar juntamente com a equipe, integrando-a, e rumando para os objetivos e metas da escola segundo Lück (2009b),

A crescente complexidade do trabalho pedagógico levou à instituição de funções diferenciadas no sistema de ensino e na escola, atribuídas a profissionais diversos. No entanto, nem sempre os membros da organização educacional estiveram preparados para essas formas mais complexas de ação e passaram a simplificá-las e a estereotipá-las, burocratizando-as e estabelecendo, desnecessariamente hierarquias e segmentações inadequadas. Assim, o que poderia ter correspondido a um avanço na educação, promoveu um dispêndio de recursos e de energia, sem resultados positivos e operacionais paralelos. $\mathrm{O}$ exagero da burocracia e da hierarquia teve como consequência, no dia-a-dia das unidades de ensino, situações como ouvir-se: "vamos fazer, porque a diretora disse!"; de ver-se uma secretária escolar não sair da secretaria, ou se o faz, dar atendimento a um aluno com má vontade, porque essa não é a sua função. A superação da visão burocrática e hierarquizadora de funções e posições, evoluindo para uma ação coordenada, passa, necessariamente, pelo desenvolvimento e aperfeiçoamento da totalidade dos membros do estabelecimento, na compreensão da complexidade do trabalho educacional e percepção da importância da contribuição individual e da organização coletiva (LÜCK, 2009b, p. 6).

Para Peter Drucker, Diretrizes, Metas e Estratégias do PNE (SEE-SP, 2010; BRASIL, 2014), a liderança é capaz de mudar conforme as circunstâncias, independente do posto de cada membro. Inclusive para ele, na era do conhecimento e informação, a ideia de "posto" será substituída pela ideia de "atribuição". O trabalho dinâmico da escola pede esse compartilhamento, essa interpenetração, que faz como que o resultado coletivo seja maior do que a soma dos desempenhos individuais, devendo ser 
colaborativo. A primeira característica importante, apontada pelos entrevistados, para o perfil do gestor é exatamente alguém que permite e fomenta a participação da equipe e da comunidade escolar.

Liderar a partir da ideia de atribuição exige do gestor, um mínimo de capacidade de compreender o que se passa na escola, e quais seus pontos fortes e fracos. Contudo, ninguém lidera uma instituição que não conhece, então para John Kotter segundo Diretrizes, Metas e Estratégias do PNE (SEE-SP, 2010; BRASIL, 2014) compreender sua organização e o ambiente onde trabalhamos é uma aptidão fundamental no exercício da liderança. Certamente não existe nada melhor para o conhecimento de uma instituição como a escola, que a base de sua força de trabalho é o ser humano, e não máquinas como a indústria, do que ouvir e dialogar.

É imprescindível que uma escola que busca possuir uma gestão democrática saiba ouvir e dialogar com toda a comunidade escolar, entendendo seus problemas e limitações, buscando soluções reais e possíveis, no entanto, ouvir e dialogar são elementos indispensáveis para uma gestão democrática real e dinâmica. Assim o gestorlíder será um facilitador, um especialista em pessoas, sua atuação ajuda as pessoas a superarem limites e amarem seu trabalho (SEE-SP, 2010), sendo capaz de gerar sinergia coletiva e fazer como que as ações sejam eficazes, pois são articuladas conjuntamente.

\section{CONSIDERAÇÕES FINAIS}

O propósito desse estudo foi analisar a percepção da comunidade escolar quanto ao perfil do diretor ou gestor a partir da realidade da gestão democrática, através de uma abordagem qualitativa de caráter exploratório com a aplicação de um questionário a fim de checar as causas do problema. Os resultados obtidos apresentam que $80 \%$ dos pesquisados acreditam que não há gestão democrática implantada nas escolas estaduais, $5 \%$ que sim e $15 \%$ parcialmente. No entanto $70 \%$ afirma que a gestão participativa é maior de idade dificuldade, seguidas de $50 \%$ para recursos financeiros e $45 \%$ para a gestão de pessoas.

A maioria dos participantes entende que as ações para escola ser mais democrática estão nas áreas da gestão participativa e recursos humanos deveriam englobar ações como a elaboração do PPP em conjunto com a comunidade escolar, os professores deveriam ser ouvidos quanto as questões relacionadas a educação através de debates e esclarecimento dos resultados, a comunidade escolar deveria ser ouvida e participativa junto na tomada de decisões dentro da escola, assim melhoraria o ambiente escolar

Para uma gestão ser mais democrática foi observado que $80 \%$ referem-se a uma dimensão mais coletiva, seguida de $15 \%$ com ações de dimensão pedagógica e $5 \%$ de dimensão econômica, com atuação nas áreas de gestão dos recursos físicos e financeiros, pedagógica e nos resultados educacionais do ensino e da aprendizagem, respectivamente.

Por essa razão, o diretor que também pode ser chamado de gestor escolar ou ainda líder formal, terá como uma das características centrais do seu trabalho, o esforço contínuo de organizar os trabalhos escolares envolvendo os diferentes segmentos representativos da escola-professor, funcionários, alunos e comunidade, com isso a dimensão do gestor, terá além do papel de educador, como de buscar e alcançar os objetivos educacionais da escola, do saber e da aprendizagem dos alunos, apontamos assim, as características fundamentais do perfil do diretor, como líder. 
Para definirmos as características do diretor, destacamos $45 \%$ a permissão da participação, 30\% dialogo, 30\% liderança, 30\% ter voz, 5\% ser flexível, 5\% respeito a autoridade e $5 \%$ priorização da escola.

Quando se tem um gestor líder com postura positiva em suas ações, isso normalmente contagia a equipe que se torna motivada, sem medo de mudanças e desafios, onde o gestor dessa maneira, propícia a busca da satisfação pessoal pelo profissional que ali atua. Ser líder não é ser gerente que executa tarefas, controla recursos, administra uma estrutura, etc. Entretanto, não podemos ignorar a grande importância das habilidades humanas, que é exatamente a capacidade de trabalhar com pessoas e equipes, tornando-as participantes, responsáveis, compreendendo-as e motivando-a

A saber, que o diretor democrático deve ser um líder (ter uma visão estratégica, ser empreendedor, ser dedicado, determinado, persistente, ser entusiasmado, possuir expectativas elevadas e disposição para aceitar desafios e lidar), conduzindo à escola a consecução dos seus objetivos e metas.

Outra característica é que um gestor verdadeiramente democrático permite a participação (tem espírito de equipe e capacidade de mobilização de pessoas) de toda a comunidade escolar. Participação não apenas no processo democrático, mas no levantamento de problemas, elaboração e efetivação das decisões. Finalmente, como democracia é um processo coletivo e se faz pela participação das pessoas, as habilidades humanas, de saber ouvir (ter sensibilidade humana, empatia) e dialogar (inteligência emocional e inteligência social) é o antidoto contra $o$ autoritarismo e a pseudoparticipação.

\section{REFERÊNCIAS}

ADRIÃO, T.; CAMARGO, R. B. D. A gestão democrática na Constituição Federal de 1988. Gestão, financiamento e direito à educação: análise da LDB e da Constituição Federal. São Paulo: Xamã, p. 69-78, 2001.

BECKER, M. M.; DE SOUZA; M. L.; PARDAL, P. P. M.; SILVA, J. M. Os Desafios da Liderança Participativa e Democrática na Gestão Escolar. Revista Eletrônica Pesquiseduca, v. 8, n. 16, p. 394-407, 2017.

BRASIL. Constituição da República Federativa do Brasil. 1988. Disponível em www.planalto.gov.br. Acesso em maio de 2017.

BRASIL. Instituto Nacional de Estudos e Pesquisas Educacionais Anísio Teixeira [INEP]. Disponível em http://www.publicacoes.inep.gov.br. Acesso em maior de 2017.

BRASIL. Lei de Diretrizes e Bases da Educação Nacional [LDB] 1996. Disponível em http://portal.mec.gov.br. Acesso em maior de 2017.

BRASIL. Plano Nacional da Educação [PNE]. Plano Nacional de Educação 2014-2024: Linha de Base. 2015. Disponível em http://presrepublica.jusbrasil.com.br. Acesso em maio de 2017.

BRASIL. Lei no 13.005, de 25 de junho de 2014, Plano Nacional de Educação (PNE) Brasília: Câmara dos Deputados, Edições Câmara, 2014. 86 p. (Série Legislação, n. 125). Disponível em http://www.planalto.gov.br. Acesso em maio de 2017. 
CABRAL, M. S. N.; SOUSA, M. T. C.; DO NASCIMENTO, A. F. Estilos de liderança no contexto da gestão escolar democrática: algumas apreciações. Revista Signos, v. 36, n. 2, 2015.

CÁRIA, N. P.; LAMBERT-DE-ANDRADE, N. Gestão democrática na escola: em busca da participação e da liderança. Revista Eletrônica de Educação, v. 10, n. 3, p. 924, 2016.

CARVALHO, T. P. S. O.; COSTA, L. S.; ALEXANDRE, L. A. C. Gestão Democrática na Escola Pública Contemporânea. Id on Line Revista Multidisciplinar e de Psicologia, v. 11, n. 36, p. 385-406, 2017.

COSTA, E. M. M. P. Gestão Escolar Democrática, Tese de Doutorado, 2018. Disponível em bdigital.ufp.pt. Acesso em maior de 2017.

CURY, C. R. J. A gestão democrática na escola e o direito à educação. Revista Brasileira de Política e Administração da Educação-Periódico científico editado pela ANPAE, v. 23, n. 3, 2007.

DA SILVA, A. F.; MIRANDA, G. J. A importância da gestão democrática na implementação de uma educação de qualidade, 2019.

DE SOUZA, Â. R. Explorando e construindo um conceito de gestão escolar democrática. Educação em Revista, Belo Horizonte, v. 25, n. 3, p. 123-140, 2009.

DE SOUZA, L. T.; DE OLIVEIRA, A. M.; CARVALHO, M. A. Influência da liderança na qualidade da gestão democrática de uma escola pública. Revista Liberato, v. 18, n. 29, p. 19-28, 2017.

DOURADO, L. F. Gestão em educação escolar, 2016. Disponível em proedu.rnp.br. Acesso em maior de 2017.

FAVARIN, E. do A.; DA ROCHA, A. M. Gestão educacional inovadora: o professor na cultura digital. Regae-Revista de Gestão e Avaliação Educacional, v. 4, n. 8, p. 59-78, 2015.

FONSECA, M. 2014. Planos de governo e educação brasileira: do regime militar aos tempos atuais. Revista Brasileira de Política e Administração da Educação. v. 30, n. 2, p. 251-268. Disponível em http://seer.ufrgs.br. Acesso em maior de 2017.

GADOTTI, M. Concepção dialética da educação: um estudo introdutório. Editora Cortez, São Paulo, SP, Brasil, 2001.

GHISLENI, A. C.; COSTA, D. M. A avaliação revisitada: novos espaços do político e do pedagógico na gestão educacional. Revista Ibero-Americana de Estudos em Educação, v. 14, n. 3, p. 956-972, 2019.

GOMES, A. V. A. Gestão democrática no plano nacional de educação. GOMES, A. V. A.; BRITTO, T. F. Plano Nacional de Educação: construção e perspectivas. Brasília: Câmara dos Deputados, 2015.

GRACINDO, R. V. O gestor escolar e as demandas da gestão democrática: exigências, práticas, perfil e formação. Retratos da Escola, v. 3, n. 4, 2012.

LIBÂNEO, J. C. Organização e gestão da escola: Teoria e Prática. 5ed. Alternativa, Goiânia, 2004. 
LIMA, L. C. 2014. A gestão democrática das escolas: do autogoverno à ascensão de uma pós-democracia gestionário? Educ. Soc., Campinas, v. 35, n. 129, p. 1067-1083.

LIMA, K. Plano Nacional de Educação 2014-2024. Educação, 2014, 2024. 2015.

LOPES, M. F. D. S.; OLIVEIRA, E. R. C. D.; SILVA, N. M. R. A competência da liderança e a gestão escolar. 2016. Disponível em repositorioinstitucional.uniformg.edu.br. Acesso em junho de 2017.

LÜCK, H. A escola participativa: O trabalho do gestor escolar. 6 Edição, Editora Vozes, Rio de Janeiro, RJ, 2009a.

LÜCK, H. A evolução da gestão educacional a partir de mudança paradigmática, 2009b. Disponível em https://progestaoead.files.wordpress.com. Acesso em junho de 2017.

LÜCK, H. Gestão educacional: uma questão paradigmática. Editora Vozes Limitada, São Paulo, SP, 2017.

LÜCK, H. Liderança em gestão escolar. Editora Vozes Limitada. São Paulo, SP, 2012.

LUCKESI, C. C. Gestão Democrática da escola, ética e sala de aula. ABC educatio, v. 64, 2007.

MACHADO, C. Avaliação externa e gestão escolar: reflexões sobre usos dos resultados. Revista@ mbienteeducação,v. 5, n. 1, p. 70-82, 2017.

MAXIMIANO, A. C. A. Além da hierarquia: como implantar estratégias participativas para administrar a empresa enxuta, Editora Atlas, São Paulo, SP, 1995.

NASCIMENTO, L. P. D. " Novas formas" de gestão da escola pública: implicações sobre o processo de democratização da gestão, 2015. Disponível em monografias.ufrn.br. Acesso em março de 2017.

OLIVEIRA, E. C. D. Gestão escolar: o papel do diretor na perspectiva de uma gestão participativa. Trabalho de Conclusão de Curso da Universidade Federal do Rio Grande do Norte, 2016.

OLIVEIRA, M. A. M. Gestão educacional: novos olhares, novas abordagens, v. 1, Editora Vozes Limitada, São Paulo, SP, 2010.

OLIVEIRA, T. R. B.; RIBEIRO, M. P. Gestão escolar democrática: alternativa para a educação além do capital?. Interfacis, v. 1, n. 1, 2015.

PADILHA, A. S. A importância da participação da família na gestão escolar democrática, 2018, Universidade Federal de Santa Maria, Disponível em repositorio.ufsm.br. Acesso em março de 2017.

PARO, V. H. Administração escolar: introdução crítica. 17 Edição, Editora Cortez, São Paulo, SP, 2012.

PARO, V. H. Gestão democrática da escola pública. 3 Edição, Editora Ática, São Paulo, SP, 2006.

PARO, V. H. Gestão escolar, democracia e qualidade do ensino. Editora Ática, São Paulo, SP, 2007.

RICHARDSON, R. J. 1999. Pesquisa Social: métodos e técnicas. Editora Atlas, São Paulo, SP. 
ROBBINS, S. P., JUDGE, T. A.; SOBRAL, F. Comportamento organizacional. 14 Edição, Editora Person Prentice Hall, São Paulo, SP, 2010.

SANTOS, J. Gestão democrática. Ed. Rio de Janeiro: DP\&A, 2001. Disponível em www. estacio.webaula.com. br. Acesso em março de 2017.

SECRETARIA DA EDUCAÇÃO DO ESTADO DE SÃO PAULO [SEE-SP]. Caderno do Gestor: Gestão do currículo na escola. 1 e 3, 2010. Disponível em www.rededosaber.sp.gov.br. Acesso em março de 2017.

SHIMAMOTO, S. V. D. M. Gestão Escolar Democrática: Discursos de transformação ou conservação? 2011. Universidade Federal Fluminense, Disponível em http:// clyde.dr.ufu.br. Acesso em novembro 2019.

SILVA, A. K. V. D. Relações interpessoais: desafio para uma gestão escolar democrática, Universidade Estadual da Paraíba, 2019, Disponível em http://dspace.bc.uepb.edu.br/jspui/handle/123456789/15503. Acesso em novembro 2019.

SOUZA, D. Q. M. D. Gestão Democrática da Escola Pública: desafios e perspectiva. In Congresso Internacional De Educação, EDUCERE, VIII, Curitiba, v. 6, 2008.

TAVARES, T. M. Olhares Sobre a Gestão da Educação: Controvérsias e Desafios. Editora Appris, São Paulo, SP, 2019.

TORRES, A.; GARSKE, L. M. N. Diretores de escola: o desacerto com a democracia. Em Aberto, v. 17, n. 72, 2008.

VALERIEN, J. Gestão da escola fundamental: subsídios para análise e sugestões de aperfeiçoamento. 2 Edição, Editora Cortez, São Paulo, SP, 1993.

VIEIRA, G. D. G. Gestão escolar. de Política e Administração da Educação-Periódico científico editado pela ANPAE, Universidade Estadual da Paraíba, 2017. Disponível em http://dspace.bc.uepb.edu.br/jspui/handle/123456789/15503. Acesso em novembro 2019.

VIEIRA, S. L.; VIDAL, E. M. Gestão democrática da escola no Brasil: desafios à implementação de um novo modelo. Revista Iberoamericana de educación, v. 67, n. 1, p. 9-38, 2015. 